\title{
Predictive modelling of the behaviour of volatiles and metals in degassing arc magmas compared to the rock record
}

\section{CYRIL CHELLE-MICHOU ${ }^{1}$ AND BERTRAND ROTTIER $^{2,3}$}

${ }^{1}$ ETH Zürich

${ }^{2}$ Centre de recherche sur la géologie et l'ingénierie des ressources minérales $(\mathrm{E} 4 \mathrm{~m})$

${ }^{3}$ Université Laval

Presenting Author: cyril.chelle-michou@erdw.ethz.ch

In fossil arc magmatic systems, direct evidence for the behaviour of volatiles and metals during crystallization and degassing are mostly lacking or are equivocal to interpret. This situation hampers our understanding of the magmatic processes leading to the formation of porphyry copper deposits, to the outgassing of vast amounts of sulphur into the atmosphere or to the cycling of halogens, sulphur and metals through the arc crust.

Recently, a large body of experimental work has focussed on understanding the behaviour of sulphur, chlorine and copper in intermediate to felsic calc-alkaline magmas, undergoing crystallization and degassing under a range of pressure, temperature and redox conditions. To test the respective role of water, chlorine, and oxygen fugacity in favouring sulphur and copper degassing we have modelled magma degassing from andesitic to dacitic magmas emplaced at 2 kbar. Our model embeds experimentally-derived parametrizations for the compositional evolution of the melt, the saturation of magmatic sulphides and sulphates, and the partitioning of sulphur, chlorine and copper between melt, crystals and a magmatic volatile phase.

This model provides a framework to interpret the fluid and melt inclusion record of arc magmatic(-hydrothermal) systems, as well as the petrographic observations of magmatic sulphides and anhydrite in plutonic and volcanic rocks. It also quantifies the key role water, chlorine and oxygen fugacity in favouring the formation of porphyry copper deposits. 